\title{
Requirements Engineering and Its Role in Mobile Telephone Industry Development
}

\author{
Hafiz Faiz Rasool, Member, IACSIT, Najia Saher, Zafar Iqbal, M. Riaz Ajmal, and Sajid Arshad
}

\begin{abstract}
This paper deals with the requirements engineering( $R E)$ for developers of mobile telephones, and its role in mobile telephones technology development. $R E$ is one of the most critical task in mobile telephones industry activities, because of the highly dynamic market change, especially in mobile telephony devices to meet the market needs in short time. In mobile telecommunication devices, to meet the market needs in short time RE must be properly involved in the life cycle of the development process. However, it is too often regarded as useless and overly time consuming, because nonfunctional and functional requirements can be elicited using separate teams and process, on the other hand by using $\mathrm{RE}$ process in product life cycle, $\mathrm{RE}$ tools increase productivity and quality, customer is properly managed. In this paper we proposed main problems that stand on the way towards an optimal RE practices in mobile telephone sector. Successful product development depends gradually on collaboration between the many individuals and teams involvement including system engineers, software engineers, electronic and telecommunication engineers and the engineering director, also a high degree of cooperation between the industry and research world is essential in order to achieve success in $\mathbf{R E}$ phase of product development in mobile phone industry.
\end{abstract}

Index Terms-Requirements engineering, mobile phone industry, requirements elicitation, telecommunication industry.

\section{INTRODUCTION}

In the past few years wireless mobile telephones are so simple, limited features, large in size, with the passage of time peoples expect for more than just a cell phone, extra features such as MP3 player, Video player, e-mail capabilities, web browsers and various productivity applications, we can say that connectivity has converged with entertainment and productivity. Telecommunication companies are in competition to add the features that customer want in daily life.

Now a days peoples want a small and smart mobile phone with light weight and extra functionality, different people show different demands, so it depend the company how it satisfy the users with their needs based on RE. Every Telecommunication industry try to get a good place in a market by attracting the peoples by the new product with new features in flexible way regarding software and hardware [1].

\footnotetext{
Manuscript received January 6, 2014; revised March 27, 2014.

The authors are with the Islamia University of Bahawalpur, Pakistan (email: engr.faiz07@iub.edu.pk, zriqbal32,@gmail.com,

sajidarshad90@hotmail.com).
}

\section{Build Your Own PhONE With PRoJect ARA}

Android phones attracts the peoples by providing the flexibility in installing the software applications in own devices as they want to use. Now a days the Google owned company Motorola has just announced the project Ara, a free, open hardware platform for creating highly modular smartphones [2]. An endoskeleton, or structural frame, holds the smartphone modules of the owner's choice, such as a display, keyboard, or extra battery. To attract the people Motorola want to do for hardware what the Android platform has done for software. The design for Project Ara consists of an endoskeleton (endo) and modules. The endo is the structural frame that holds all the modules in place. A module can be anything, from a new application processor to a new display or keyboard, an extra battery [3]. Fig 1 shows a modular smart phone, a user fitting a camera in his device.

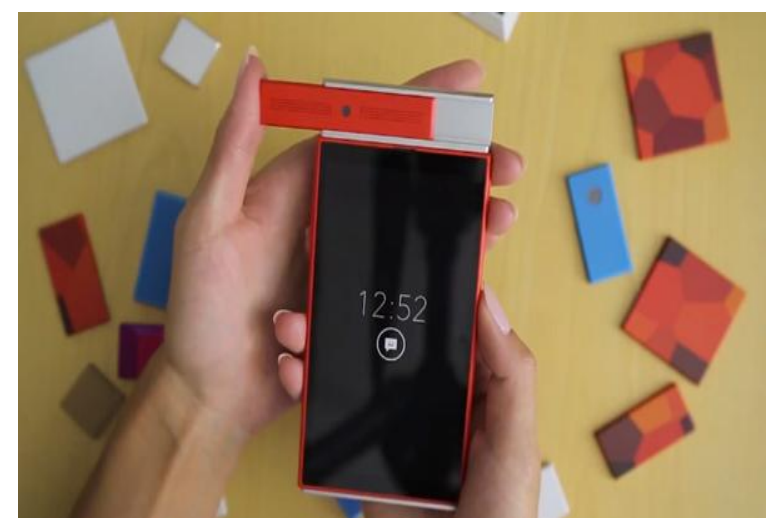

Fig. 1. A user fitting a camera in his mobile phone [2], [3].

\section{ROLE OF RE IN MOBILE TELEPHONE INDUSTRY}

One problem with the software industry is the lack of common definitions for terms we use to describe aspects of our work. Different observers might describe the same statement as being a user requirement, software requirement, functional requirement, system requirement, technical requirement, business requirement, or product requirement. A customer's definition of requirements might sound like a high-level product concept to the developer. The developer's notion of requirements might sound like detailed user interface design to the user. This diversity of definitions leads to confusing and frustrating communication problems[4], [5].

Consultant Brian Lawrence suggests that a requirement is "anything that drives design choices" (Lawrence 1997). Many kinds of information fit in this category. The IEEE Standard Glossary of Software Engineering Terminology 
(1990) defines a requirement as

1) A condition or capability needed by a user to solve a problem or achieve an objective.

2) A condition or capability that must be met or possessed by a system or system component to satisfy a contract, standard, specification, or other formally imposed document.

3) A documented representation of a condition or capability as in 1 or 2 .

Requirements engineering is a vital process that helps companies manage complex requirements, improve team collaboration and ultimately produce high-quality products more cost-effectively [6], [7]. The proposed paper explores requirements engineering and how it affects product development and engineering in the industrial segment. It also discusses the best practices and benefits of requirements engineering [8]. A high-quality software requirements specification (SRS) is an essential precondition for the development of a successful software system. High-quality in requirements engineering refers to criteria like consistency, completeness, correctness, clarity, structure, unambiguity, minimality, traceability, and maintainability [9], [10]. (See Fig. 2).

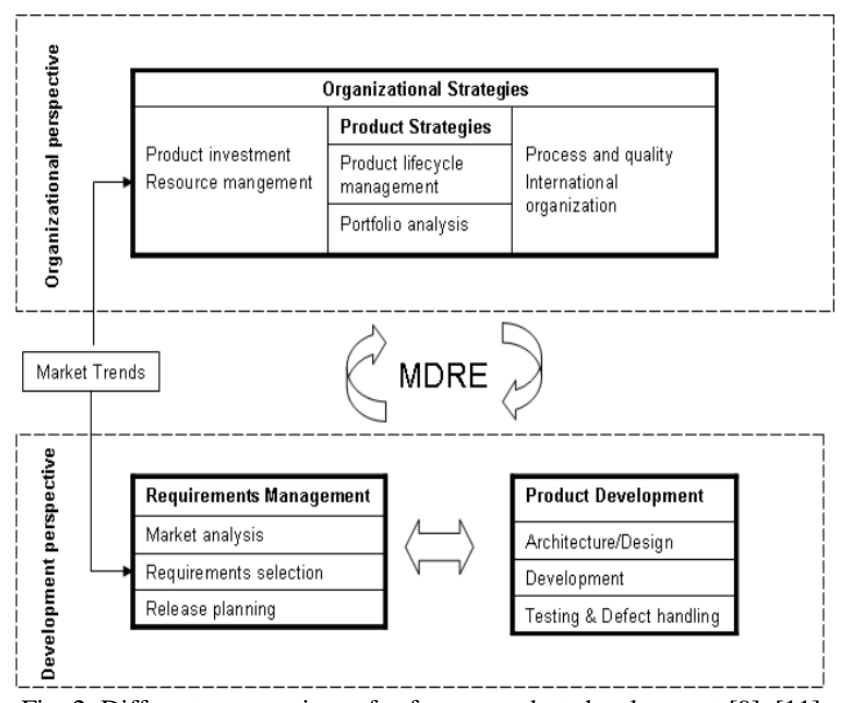

Fig. 2. Different perspectives of software product development [9], [11].

\section{The Chalenges of ReP In Mobile PhONe Industry}

\section{A. Lack of Global Standards}

Requirements management for mobile telephones is very complex because of the lack of a global standard transmission protocol ,the numerous product customizations and the variations due to local standards[12], [13].

\section{B. Complexity Due to Increase in Number of Survices}

Complexity in requirements engineering process increases by increasing the number of services in the mobile telephone devices, device take extra memory and make the system so complex that it show low performance and reduce processing speed also[14]-[16].

\section{Reuse and Legacy Management}

New requirements must be added in upcoming mobile phone devices by using the existing relevant software features, must be change from the previous products [16]-
[18]. New features in upcoming products attracts the users. These are the features that make the telephony devices more complex [19].

\section{PROBlems For REP DEVELOPMENT IN MOBILE TELEPHONE DEVICES}

Ambiguous requirements lead to ill-spent time and rework.

Gold-plating by developers and users adds unnecessary features.

Insufficient user involvement leads to unacceptable products [20].

Inaccurate Planning, Incompletely defined requirements make accurate project planning and tracking impossible.

Overlooking the needs of certain user classes (stake holders) leads to dissatisfied customers.

Minimal specifications lead to missing key requirements. Variations in user demands also effect the REP [21].

\section{MeEting Chalenges IN THE TElePhONE InDUSTRY}

Requirements engineering can help overcome the following challenges in developing technology within the telecommunications/telephone industry.

\section{A. Cost-Effect Innovation}

Telecommunications networks need innovative products to win market share. But to improve profit margins, they need to differentiate their brands and enhance performance while at the same time accelerating lifecycles, reducing costs, assuring quality and delivering product excellence, also RE is not integrated with the development methods [12], [21].

\section{B. Better Collaboration with Telecomunication Networks}

Reducing development costs and managing complexity require close partnership and integration between network technology providers and the telecommunications enterprises they serve. That means making some fundamental changes in the way they do business [12]. They need to align design and product development with rapidly changing customer requirements while increasing product quality and reducing time to market and cost. Most of all, they must capture the requirements of their network customers quickly, reliably and in a collaborative environment [12], [22].

\section{Gap between Requirements and Software Architecture}

The biggest effort in production of mobile telephones goes into software development. In a market where a new product family needs to be launched every few months, software development can involve fatal delays. In most cases, the root of the problem can be found in weak connection between the set of requirements and software architecture. When requirements and architecture evolve separately, the product failure alarm should ring. These problems occurs when the staff developing the architecture has little voice during elicitation of requirements [16]. Symmetrically, the people that perform requirements elicitation are not consulted during the architecting phase. 
Only a few key requirements are considered when developing the architecture, and the rest of the work is left to the component developers. Hence, in this paper we proposed that software architecting and requirements engineering cannot be separated. Software architecture is the high level solution to the problems posed by the requirements. The set of requirements should develop hand in hand with the architecture [23].

\section{CONCLUSION}

Efficient and cost-effective product development is key to success in today's global development environments. A requirements engineering approach can help product development organizations work in harmony as they communicate and collaborate through standardized processes for requirements management. When requirements are traced and managed across teams and the development lifecycle, enormous amounts of rework can be avoided. Looking at the future, we foresee that an increasing number of projects will experience problems or, in extreme cases, failure due to a bad REP. Finally, RE helps organizations enhance collaboration among globally distributed teams and suppliers. This means that virtually all stakeholders can be involved in the requirements management process and be confident that everything they do is aimed at fulfilling customer requirements. The requirements engineering best practices of complexity management, requirements traceability and collaboration can help you reduce time to market, cut costs, deliver higher-quality products, improve customer satisfaction, simplify regulatory compliance and achieve a greater competitive advantage.

\section{ACKNOWLEDGMENT}

We wish to thank all our respected teachers and friends for their excellent contributions and support for the completion of this paper.

\section{REFERENCES}

[1] IBM Software Research Group, "Requirements engineering for mobile telecommunications technology development," IBM Corporation, U.S.A Zave, p. 1997, 2009.

[2] Motorola announces project ara, an open, modular smartphone hardware platform. [Online]. Available: http://www.androidpolice.com/2013/10/28/holy-shit-motorolaannounces-project-ara-an-open-modular-smartphone-hardwareplatform/.

[3] Motorola unveils project Ara for custom smartphones. [Online]. Available: http://news.cnet.com/8301-1035_3-57609735-94/motorolaunveils-project-ara-for-custom-smartphones/.

[4] K. E. Wiegers, Software Requirements, 2nd edition, Microsoft Press, 2003.

[5] A. Aurum and C. Wholin, Engineering and Managing Software Requirements, Berlin Heidelberg: Springer-Verlag, 2005.

[6] K. Nuseibeh, B. Kramer, J. Finkelstein et al., "A framework for expressing the relationships between multiple views in requirements specification," IEEE Transactions on Software Engineering, vol. 20, no. 10, pp. 760-773, 1994.

[7] F. Modugno, N. G. Leveson, J. D. Reese, K. Partridge, and S. D. Sandys, "Integrating safety analysis of requirements Specifications," in Proc. 3rd IEEE International Symposium on Requirements Engineering, Annapolis, USA, January 6-10, 1997, pp. 148-159.

[8] P. Loucopoulos and C. Potts, Requirements Engineering Journal, Springer Verlag.
[9] B. Tschaitschian, C. Wenzel, and I. John, "Tuning the quality of informal software requirements with KARAT," in Third International Workshop on Requirements Engineering: Foundation for Software Quality, E. Dubois, L. Opdahl, and K. Pohl, Eds., Barcelona, Spain, 1997.

[10] A. Davis, S. Overmyer, K. Jordan, and J. Caruso, "Identifying and measuring quality in a software requirements specification," IEEB, 1993.

[11] A. Gomes and A. Pettersson, "Market-driven requirements engineering process model - MDREPM," M.S. thesis, School of Engineering Blekinge, Institute of Technology, Sweden, January 2007.

[12] A. Maccari, "The challenges of requirements engineering in mobile telephones industry," in Proc. Tenth International Workshop on Database and Expert Systems Applications, Florence, 1999.

[13] I. Jacobson, G. Booch, and J. Rumbaugh, The Unified Software Development Process, Addison-Wesley, 1999.

[14] A. Karhinen, M. Sandrini, and J. Tuominen, "An approach to manage variance in legacy systems," in Proc. the 3rd European Conference on Software Maintenance and Reengineering, Amsterdam, NL, 1999.

[15] R. L. Glass, Software Runaways, Prentice-Hall, USA, 1998.

[16] J. Kuusela, A. Karhinen, and A. Maccari, "Justification for special purpose object oriented software development methods," in Proc. the Third International Conference on Object Oriented Methodology, Saint Petersburg, Russia, 1998.

[17] J. Kuusela, "Architectural evolution, Nokia mobile phones case," in Software Architecture, P. Donohoe, Ed., Boston, USA: Kluwer Academic Publishers, 1999.

[18] W. Frakes, W. B. Frakes, and C. J. Fox, "Sixteen questions about software reuse," Communications of the ACM, vol. 6, no. 38, June 1995.

[19] B. Curtis, H. Krasner, and N. Iscoe, "A field study of the software design process for large systems," Communications of the ACM, vol. 31 , no. 11,1988

[20] K. P. Klaus, Requirements Engineering Fundamentals, Principles, and Techniques, Springer-Verlag Berlin Heidelberg, 2010.

[21] R. Pressman, Software Engineering: A Practitioner's Approach, 7th ed., McGraw-Hill, 2009.

[22] C. Liu, Q. Zhu, K. A. Holroyd, and K. E. Seng, "Status and trends of mobile-health applications for iOS devices: A developer's perspective," The Journal of Systems and Software, vol. 84, pp. 20222033, 2011.

[23] J. Pernsta, R. Feldt, and T. Gorschek, "The lean gap: A review of lean approaches to large-scale software systems development," The Journal of Systems and Software, vol. 86, pp. 2797-2821, 2013.

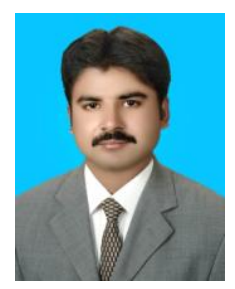

Hafiz Faiz Rasool received his B.Sc. in electronics and computer engineering from The Islamia University of Bahawalpur, Pakistan in 2011. In 2011 he joined Pakistan Telecommunication Company Limited (PTCL) where he worked as an internee engineer. Currently he is working as a lecturer in College of Engineering and Technology at The Islamia University of Bahawalpur, Pakistan. He is also pursuing MS in software engineering from The Islamia University of Bahawalpur, Pakistan. He has many publicatins in the field of embeded systems such as VLSI \& FPGA based system designing. His research interests include computing and digital electronics system designing, behavioural modeling. $\mathrm{He}$ is a member of International Association of Computer Science and Information Technology (IACSIT) and Pakistan Engineering Council (PEC).

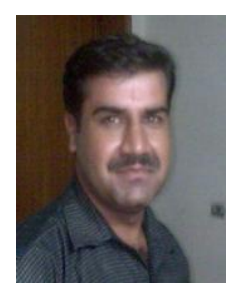

Zafar Iqbal received his B.Sc. degree in software engineering from the The Islamia University of Bahawalpur, Pakistan, in 2004 and master degree in computer science in 2006, respectively. In 2008, he joined the Next Bridge Technologies Software Company at Lahore Pakistan, as a software engineer, and in 2010 became a senior software engineer. Then he joined another software company Hiwebsol and started web programming and apply his good knowledge in web programming and got expertise in latest web technologies of the era. He is currently pursuing MS in software engineering from The Islamia university of Bahawalpur, Pakistan. His area of interests include embedded system designing, web development networking and communication. 


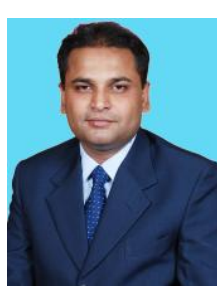

M. Riaz Ajmal received his B.Sc. degree in computer science in 2002 from The Islamia University of Bahawalpur, Pakistan ,and master in information technology in 2006 from Sarhad University of Science and Information Technology, Peshawar, Pakistan. He is currently pursuing MS in software engineering from The Islamia University of Bahawalpur, Pakistan. He is serving humanity from last 10 years and working at Command \& Control Room Incharge, Punjab Emergency Services (RESCUE 1122), Bahawalpur, Pakistan.

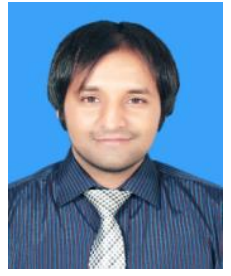

Sajid Arshad was borrn in Bahawalpur, Pakistan. $\mathrm{He}$ received his B.Sc, and MSc degrees in computer science in 2006 and 2009 respectively. $\mathrm{He}$ is currently pursuing MS in software engineering from The Islamia University of Bahawalpur, Pakistan. His area of interests include embedded system designing, web development networking and communication. 